\title{
CASTING A NET FOR KNOWLEDGE
}

\section{Collaboration following the Fukushima disaster led to discoveries that could improve management of bluefin tuna.}

\section{BY SMRITI MALLAPATY}

$\mathrm{F}$ ew catches are as highly prized as the Pacific bluefin tuna. A sizable adult can sell for US $\$ 300,000$-plus at Tokyo's Tsukiji fish market. But while sushi-lovers savour its taste, the giant fish's pre-plate life is less well understood. Groups of scientists on both sides of the Pacific are beginning to shed some light on it.

Their work could have profound implications for the survival of the overfished and endangered bluefin. Their story reveals some of the ways that environmental science engages with the real world, under tough public scrutiny. It begins with the devastating tsunami and ensuing nuclear disaster on 12 March 2011 in Fukushima, a region on the central-eastern coast of Japan's main island of Honshu.

\section{IN THE PUBLIC EYE}

Several months after the nuclear spill, in an effort to measure the extent of contamination, marine ecologist, Daniel Madigan, at Stanford University, teamed up with marine biogeochemist, Nicholas Fisher, at Stony Brook University in New York, to test radiation levels in Pacific bluefin tuna that had migrated to the shores of San Diego, California. "When an accident like Fukushima happens, you have to use the opportunity to learn," says Madigan, who recently moved to the Gulf of California International Research Center in Mexico.

All of the 15 fish they sampled carried traces of radioactive isotopes known to have been released at the Fukushima Daiichi nuclear power plant - caesium-134 and caesium-137. The levels were considerably higher than those caused by weapons testing in the Pacific in the 1960s.

The researchers' results were published in May 2012, and covered widely by the media. Among the Earth and environmental science journals tracked by the Nature Index, it was one of the most talked about article in 2012 as measured by Altmetric score.

"There was instant panic," says Fisher. "Everyone wanted to know whether the tuna was safe to eat." For the scientists, it was a loaded question. A 'yes' would green-light the continued fishing of a vulnerable species,

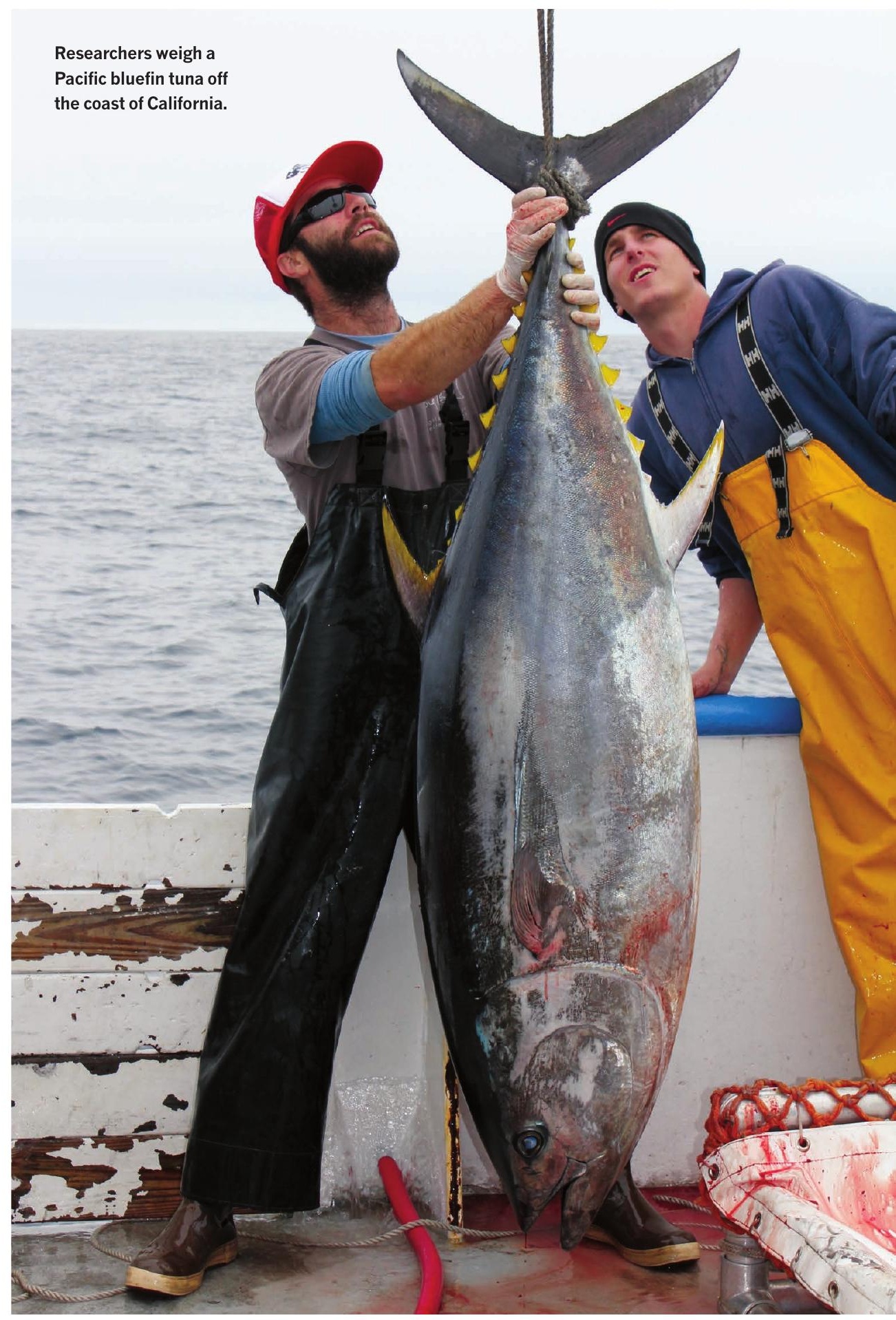


and stoke allegations of the scientists acting as decoys for the nuclear industry. A 'no' could rouse rumblings of conservationists posing as scientists, antagonize fishermen and devastate an important industry.

The bottom line was yes. In a follow-up study quantifying the risk, the researchers calculated that a person consuming 24 kilogrammes of Pacific bluefin tuna would absorb an ionizing radiation of 0.9 microsieverts about the exposure that they would get from eating nine bananas, which contain naturally occurring isotopes of potassium.

As a bonus, the investigation established that radioactive or stable isotopes could be used to track the movement of fish - a cheaper and less intrusive approach than the conventional method of attaching tiny devices.

In October 2012, Fisher was invited to a meeting at the European Commission to present his work. He showed that fish caught in the open ocean were unlikely to be toxic, eliciting "a sigh of relief," he says. Fish caught within tens of kilometres of the Fukushima shore, especially those along the ocean floor, might still pose a public health risk. The meeting concluded that additional monitoring measures for imports from the non-Japanese Pacific introduced after 2011 were "no longer recommended".

\section{CAUTIONARY TALE}

As the bluefin tuna saga unfolded in the public eye, behind-the-scenes machinations were sparking other Fukushima-related research. Weeks after the incident, geoscientist, Michio Aoyama, at the Japan Meteorological Research Institute, under the Japan Meteorological Agency (JMA), and radiochemist, Ken Buesseler, at the Woods Hole Oceanographic Institution in the US had established that Fukushima represented the largest ever accidental release of radioactivity to the marine environment, even greater than in the Black and Baltic seas in 1986 following Chernobyl.

Aoyama, who has since left the government agency to work at Fukushima University, has accumulated substantial knowledge on the movement of Fukushima-derived radionuclides in the ocean, which is valuable to operators of coastal nuclear power plants. If an accident were to happen today, he says, they know what to expect.

Buesseler and Aoyama have continued to co-author papers. Their research has been cited in the ongoing trade dispute between Japan and South Korea over restrictions to seafood imports from prefectures in northeastern Japan. In February 2018, the World Trade Organization ruled that South Korea's measures restricted trade unnecessarily, but South Korea appealed the decision in April.

\section{BIG FISH}

Until recently, researchers assumed only a minority of the tuna population embarked on the journey from their spawning grounds

\section{SOURCES OF FUNDING}

The graph shows funding for Earth and environmental science research from select major funders from 2006-2016. The United States National Science Foundation funded more research in the discipline than any other institution in the world. It averaged close to 2,000 grants a year worth a total of more than US $\$ 10$ billion. Comparable figures for Chinese funders are not available.

The total number of grants is in square-brackets.

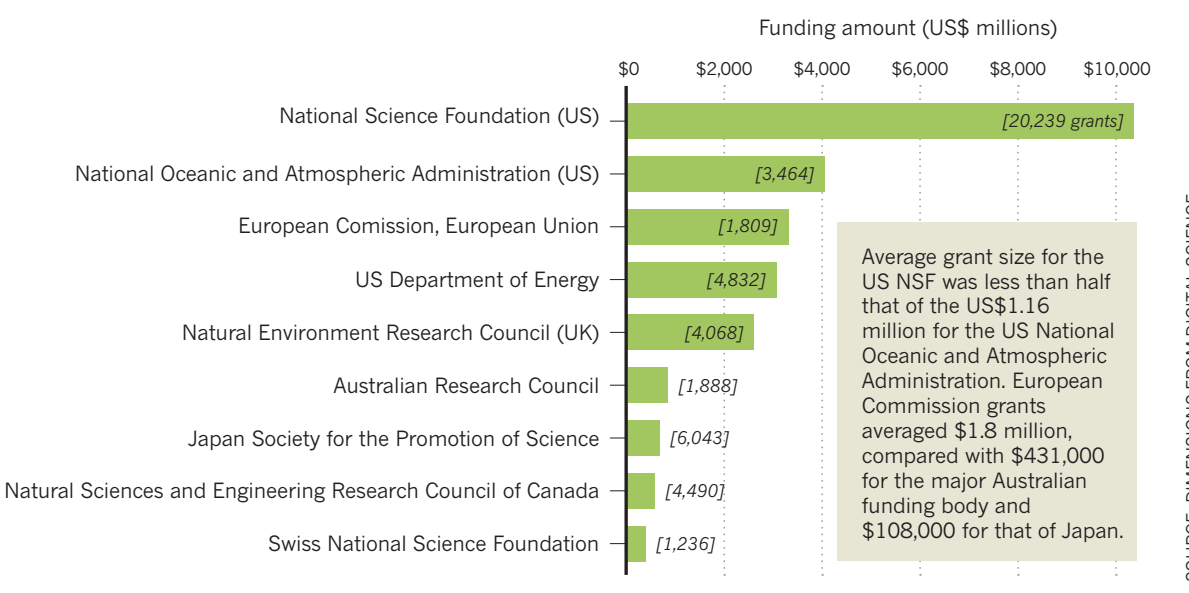

\section{GETTING TOGETHER}

International collaboration on high-quality research is increasing in all the natural science disciplines, but among them, Earth and environmental sciences had the lowest proportion of articles in journals included in the index produced within a single institution and the highest proportion of internationally collaborative articles since 2012 (right).

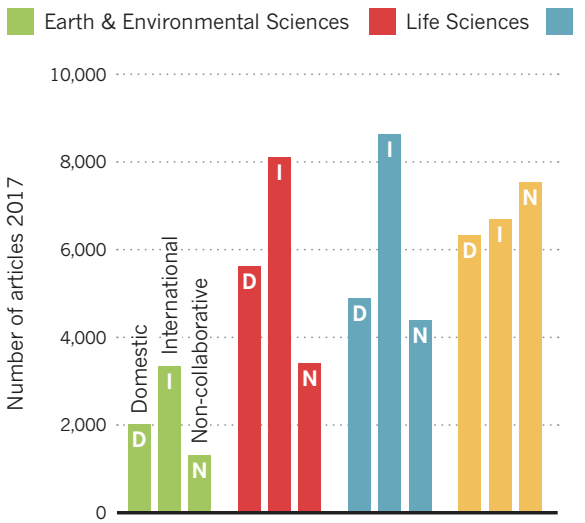

Physical Sciences

Chemistry

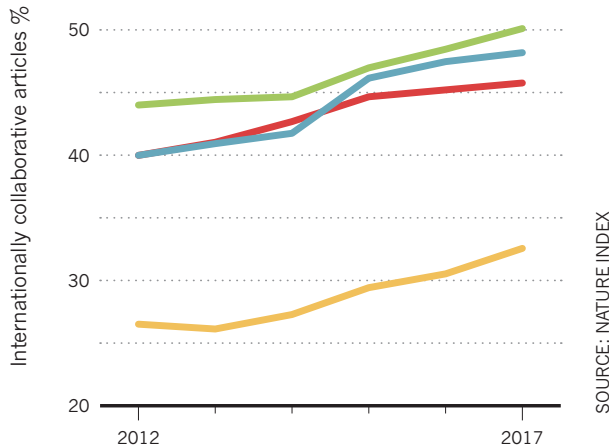

around Japan to North America. In a paper published in March 2017, a group of Japanese researchers used the tracing technique proposed by Madigan and Fisher to test this belief.

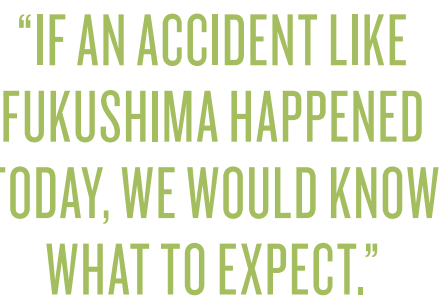

The researchers at the National Research Institute of Far Seas Fisheries (NRIFSF) and the National Research Institute of Fisheries Science tested 155 fish caught along Japan's western coast for stable nitrogen isotopes, which are more abundant in North America. By the age of seven, almost all of the sampled fish carried elevated levels of the isotopes, indicating they had made the round trip.

The Japanese discovery suggested that fishing practices in North America affected the entire bluefin population, turning tuna management in the region "from something you can ignore to something that matters a lot," says Madigan.

The cooperation on bluefin tuna was the final impetus for a long-envisaged partnership between Madigan in Mexico, the NRIFSF in Japan, and Texas A\&M University and the National Oceanic and Atmospheric Administration in the US. The researchers plan to share biological samples from across the Pacific to study tuna population dynamics, which could help to better predict how projected changes in the environment will affect

"We hope to put together a comprehensive picture of both sides of the ocean," says Madigan. their movement. 